\title{
Self-medication in ophthalmology - a northern Indian tertiary hospital experience
}

\author{
Rohini Gupta*, Pavan Malhotra
}

Department of Pharmacology and Therapeutics, Acharya Shri Chander College of Medical Sciences, Sidhra, Jammu, Jammu and Kashmir, India

Received: 07 September 2016 Accepted: 12 October 2016

\section{*Correspondence to:}

Dr. Rohini Gupta,

Email: rohinigupta299@ gmail.com

Copyright: (C) the author(s), publisher and licensee Medip Academy. This is an openaccess article distributed under the terms of the Creative Commons Attribution NonCommercial License, which permits unrestricted noncommercial use, distribution, and reproduction in any medium, provided the original work is properly cited.

\begin{abstract}
Background: The objective of the study was to identify practice and pattern of self-medication use among new patients attending ophthalmology OPD in a tertiary care hospital of north India. Self-medication practice is a common phenomenon all over the world but it has been reported to be very common in the developing countries especially in India. When consumers self-medicate without consulting the eye care giver, the issues of safety and irrational use of drugs arise.
\end{abstract}

Methods: A cross-sectional questionnaire based, observational study was planned among the patients reporting for the first time to Ophthalmology OPD in ASCOMS, Jammu. The patients enrolled in the study were randomly selected in the age group $\geq 18$ years. Detailed history regarding self-medication prior to reporting to OPD was obtained. A questionnaire elucidating details of selfmedication regarding history of ocular self-medication, type of ocular medication used, their reasons for resorting to ocular self-medication etc. was provided to them. All participants were informed about the scope and purpose of the study. An informed consent was obtained in every case prior to being given the questionnaire.

Results: A total of 296 responders were interviewed. Among these 122 (41.2\%) admitted to have used eye medicines before coming to hospital. Redness in 38 $(31.1 \%)$ cases was the most common complaint for which the patients opted self-medication. $49(40.2 \%)$ patients did not know what drug they had used. Among the various drugs used, the commonest was the antibiotic eye medication in $33(27 \%)$ patients followed by steroids $13(10.7 \%)$. Among the responders $9(7.3 \%)$ experienced side-effects after self-medication. Main factors influencing self-medication were advice from friends/relatives, living far from hospital and high cost of treatment at the hospital.

Conclusions: Self-medication with eye medicines is common among the population interviewed. Educating the public about the dangers of self-diagnosis and treatment, possibly leading to delay in detection of more serious underlying ailments is essential.

Keywords: Eye medicines, Self-medication, Tertiary eye care centre

\section{INTRODUCTION}

Self-medication is defined by the World Health Organization (WHO) as the selection and use of medicines by individuals to treat self-recognized illnesses or symptoms. ${ }^{1}$ Self-medication is also defined as obtaining and consuming one or more drug(s) without the advice of a physician either for diagnosis, prescription or surveillance of the treatment. ${ }^{2}$
Apart from being a common phenomenon all over the world it has been reported to be very common in the developing countries. ${ }^{3}$ Self-medication behaviour includes purchasing drugs without a prescription, using leftover doses from previous prescriptions, sharing drugs with other family members or social groups, or misusing the medical prescription either by prolonging, interrupting or modifying the dosage and the administration period. ${ }^{4-6}$ 
While first-aid measures are being widely advocated for cuts, foreign particles, chemical splashes and physical trauma to the eyes, the providers and techniques are well specified to lessen the risk of permanent damage caused by eye injuries. ${ }^{7}$ Thus, a wide spectrum of symptoms and pathologies are lessened by this practice, with eyeconditions being no exception.

Health care professionals have a key role to play in providing patients with assistance, advice and information about medicines available for selfmedication. Thus, it will be a responsible act for patients to seek assistance from any health professionals regarding proper selection or use of non-prescription drugs because it is well known that the self-medication attitude and practice carries pharmacological and toxicological risks ${ }^{8}$ not only related to the potential severe side-effects of the topical drug itself, but also dangerous as a result of inappropriate treatment or failure to seek prompt medical care, thus leading to a postponement in diagnosis and, in turn to unintended consequences.

The public interest will best be served when selfmedication is responsible, only undertaken when it is appropriate to do so and advice is always given to seek a consultation with a physician when that is necessary. Regarding self-medication in ophthalmic practice, the evidence is scarce in Indian population. Therefore, due to lack of much of the evidence related to self-medication in Indian population and in view of the potential risk of adverse effects that could be associated with inappropriate use of drugs for what may seem like a minor eye problem we carried out this study to determine the prevalence of self-medication practices among patients with ocular problems, factors influencing selfmedication, the side-effects encountered and whether the medicines are used rationally.

\section{METHODS}

A cross-sectional questionnaire based, observational study was planned among the patients reporting for the first time to Ophthalmology OPD in ASCOMS, Jammu. The patients enrolled in the study were randomly selected in the age group $\geq 18$ years. Detailed history regarding self-medication prior to reporting to OPD was obtained. A questionnaire elucidating details of self-medication regarding history of ocular self-medication, type of ocular medication used, their reasons for resorting to ocular selfmedication etc. was provided to them.

All participants were informed about the scope and purpose of the study and were informed that it shall be voluntary to participate, without any compensation and their medical assistance will not be compromised if they will refuse or will decide to participate in the survey. An informed consent was obtained in every case prior to being given the questionnaire.

\section{RESULTS}

Table 1: Demographic variables of the respondents.

\begin{tabular}{|lll|}
\hline Variables & Frequency & $\%$ \\
\hline Sex & & \\
\hline Male & 84 & 68.8 \\
\hline Female & 38 & 31.1 \\
\hline Age & & \\
\hline $18-30$ & 26 & 21.3 \\
\hline $31-50$ & 53 & 43.4 \\
\hline $51-70$ & 34 & 27.8 \\
\hline 70 or older & 9 & 7.3 \\
\hline Education & & \\
\hline Primary & 8 & 6.5 \\
\hline Secondary & 36 & 29.5 \\
\hline Higher Education & 48 & 39.3 \\
\hline Illiterate & 30 & 24.5 \\
\hline
\end{tabular}

Table 2: Conditions that led to self-medication.

\begin{tabular}{|lll|}
\hline Condition & Frequency & $\%$ \\
\hline Red eyes & 37 & 30.3 \\
\hline Painful eyes & 18 & 14.7 \\
\hline Poor vision & 6 & 4.9 \\
\hline Teary eyes & 19 & 15.5 \\
\hline Itchy eyes & 26 & 21.3 \\
\hline Discharge & 4 & 3.2 \\
\hline Injury & 0 & 0 \\
\hline Cataract & 4 & 3.2 \\
\hline Swelling of the eyes & 8 & 6.5 \\
\hline $\begin{array}{l}\text { Patients who do not } \\
\text { remembered the name } \\
\text { of the eye medicine } \\
\text { used }\end{array}$ & $49(40.1 \%)$ \\
\hline $\begin{array}{l}\text { Patients who } \\
\text { remembered the name } \\
\text { or showed the sample } \\
\text { of medication used }\end{array}$ & \\
\hline
\end{tabular}

Table 3: Type of ocular medication used.

\begin{tabular}{|l|l|l|}
\hline Drugs & Frequency & $\%$ \\
\hline Antibiotics & 29 & 39.7 \\
\hline Steroids & 17 & 23.2 \\
\hline NSAIDS & 8 & 6.5 \\
\hline Vasoconstrictors & 3 & 4.1 \\
\hline Saline solution & 1 & 1.3 \\
\hline Anti-allergic & 7 & 9.5 \\
\hline $\begin{array}{l}\text { Other drugs not } \\
\text { included previously }\end{array}$ & 8 & 10.9 \\
\hline
\end{tabular}

A total of 296 patients were interviewed. Among these $122(41.2 \%)$ admitted to have used eye medicines before coming to the hospital. Demographic features of respondents are shown in Table 1. Ocular problems that 
led respondents to use eye-medicines are shown in Table 2. Redness in $38(31.1 \%)$ was the most common complaint for which the patients opted self-medication followed by itching in eyes in 27 (22.1\%). Among the respondents $49(40.2 \%)$ of the patients were not aware of the names of the eye medicines used. 73 (59.8\%) of the patients remembered the names or showed the sample of the medication used.

Table 4: Factors influencing self-medication.

\begin{tabular}{|lll|}
\hline Factors & Frequency & Percentage \\
\hline I Know what to do & 4 & 3.2 \\
\hline Complaints are minor & 7 & 5.7 \\
\hline $\begin{array}{l}\text { Advice from family } \\
\text { members/friends }\end{array}$ & 57 & 46.7 \\
\hline $\begin{array}{l}\text { Long waiting time at } \\
\text { the hospital }\end{array}$ & 3.2 \\
\hline $\begin{array}{l}\text { High Cost of } 15 \\
\text { treatment at the } \\
\text { hospital }\end{array}$ & 12.2 \\
\hline No reason/Busy & 3 & 2.4 \\
\hline $\begin{array}{l}\text { Non availability of } \\
\text { doctors/Living far }\end{array}$ & & 26.2 \\
from hospital & & \\
\hline
\end{tabular}

Table 5: Reasons for reporting to OPD.

\begin{tabular}{|lc|}
\hline Reasons & $\%$ \\
\hline Failure to improve & 63.9 \\
\hline Suboptimal response & 28.6 \\
\hline Worsening of condition & 7.3 \\
\hline
\end{tabular}

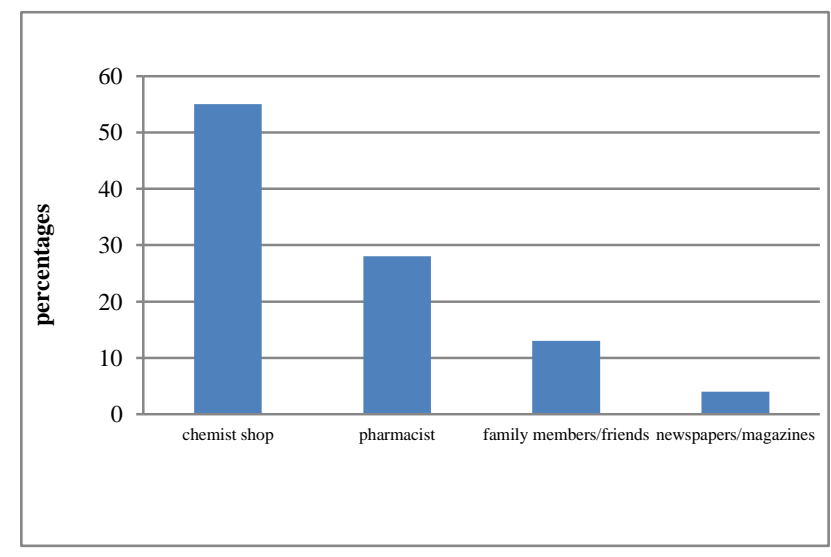

Figure 1: Sources of medicines used for selfmedication.

The names of the medicines used are shown in Table 3. Of the various drugs used, antibiotics constituted the highest group of medications used in 29 (39.7\%) followed by steroids in $17(23.2 \%)$. The patients obtained the medications from different sources. These are shown in Figure 1. The most common source from where the patients obtained the drug was the chemist shops in 69 $(56.5 \%)$ of the patients.
Table 4 shows the factors that influenced respondents to self-medicate. Advice from family friends and relatives in $57(46.7 \%)$ living far from hospital in $32(26.2 \%)$ and high cost of treatment at the hospital in $15(12.2 \%)$ patients were the major motivating factors for selfmedication.

Table 6: Side-effects experienced by respondents after self-medication.

\begin{tabular}{|ll|}
\hline Side-effects & Frequency \\
\hline Excessive tearing & 3 \\
\hline Discharge & 2 \\
\hline Increased pain & 1 \\
\hline Inflammation of the eye & 2 \\
\hline Increased irritation & 0 \\
\hline Corneal ulceration & 1 \\
\hline Blurring of vision & 2 \\
\hline $\begin{array}{l}\text { Total patients who } \\
\text { experienced side-effects after } \\
\text { self-medication }\end{array}$ & $11(9 \%)$ \\
\hline
\end{tabular}

Various reasons for which the patients reported to OPD are shown in Table 5. Among these failure to improve was the main reason seen in $77(63.1 \%)$ of the patients. $11(9.1 \%)$ of the respondents experienced side-effects after self-medication.

Table 6 shows the different side-effects experienced by the patients. Inflammation of the eye, increased irritation, excessive tears were among the major side-effects experienced by the respondents.

\section{DISCUSSION}

The present study has shown that about $41.2 \%$ of the respondents used eye medicines before coming to hospital. Self-medication by people with ocular problems has been reported in several studies. ${ }^{9,10}$ In our study, redness in $38(3.1 \%)$ was the most common complaint for which the patients opted self-medication. Similar findings were reported in studies done by Kadri $\mathrm{R}$ et al. ${ }^{11}$ and Tayanithi et al. ${ }^{12}$ where people with red eyes and those with itchy eyes respectively self-medicated more. Patients with redness in eyes could also be suffering from more serious underlying conditions like uveitis, keratitis or acute angle closure glaucoma which require immediate and precise treatment. There will be an inevitable delay in obtaining expert treatment from a qualified ophthalmologist when the patient opts for selfmedication.

Most of the patients had come to the hospital due to failure in the improvement of the ocular ailments for which they opted self-medication. In our study $59.8 \%$ of the patients knew the names of the medicines used. $40.2 \%$ of the respondents were not aware of the names of the medicines used. Not knowing the names of the medicines used by the patients who practice self- 
medication was also reported in a study by Godeliver A.B. kagashe. ${ }^{13}$ This puts the health care worker in a difficult position when trying to help the patient as he/she may not know whether the drug taken may interact with the one he/she is going to prescribe. Thus, this practice of non-prescription drug use, as well as the potential for therapeutic misadventure is a serious health issue and requires the attention of all stakeholders to reduce the burden.

In our study, Antibiotics in $39.7 \%$ of patients was the commonest group of drugs utilized before presentation to the eye-care centre. This is in consistent with studies by Ajayi et al. ${ }^{14-16}$ This might be due to the belief that most of the eye problems are due to the bacterial infections, but the use of antibiotics in our study population was mostly for non-infective eye conditions like allergic conjunctivitis, refraction, glaucoma, corneal laceration, cataract etc., most of which do not require antibiotics. This implies that in most cases antibiotics were misused. The burden of antibiotic abuse is so high to the extent that concerns have been raised by WHO which necessitated a call on the public, prescribers, policy makers, pharmaceutical industry to ensure a responsible use of this category of pharmaceutical agents. ${ }^{17}$ Antibiotics are prescription only medicines, using them without a physician's advice is irrational.

In our study, the main influencing factor, with respect to which eye-drop to buy for self-medication, was the advice from family members and friends. This is in consistent with a study done by GE Marquez et al. ${ }^{18}$ where the advice from family members was also the main motivating factor in one of the population groups. In our study, $56.5 \%$ of the patients obtained the drug from the chemist shop. This is in contrary to the study done by GE Marquez et al. ${ }^{18}$ where the pharmacist constituted the main group. In our study, chemist shops constituted the main source of obtaining the drug by the patients. This might be due to easy accessibility of patients to these retail outlets. Thus, a better control in drug selling is needed. This could rationalize the utilization of ophthalmic medicines.

\section{CONCLUSION}

Self-medication with eye-medicines was common among patients with ocular problems. Antibiotics were the drugs mostly used while redness and itching were the most reported symptoms. Chemist shops were the major source of medicines for self-medication. Although selfmedication can be employed when urgently required, extended use of any such medication needs to be approved by an ophthalmologist. Most of the conditions required more specialized care. There is therefore a need for health education of the population on the need to desist from self-medication for eye care without seeking health advice from appropriate health care professionals.
In India, easy availability of a wide range of prescription drugs across the counter without a valid prescription, lack of stringent controls over medical advertising, low medical literacy among the population and also the compulsion to reduce health care costs seem to be the motivating factors for self-medication. Thus rules and regulations should be made stringent so that the prescription only medicines will be dispensed upon presentation of a prescription, and over the counter medicines will be dispensed for the right indication.

However, more extensive studies need to be conducted to know the actual extent of self-medication practice in ophthalmology practice. Public education on judicious use of topical ophthalmic Over the counter preparations is the need of the hour.

\section{Funding: No funding sources}

Conflict of interest: None declared

Ethical approval: The study was approved by the Institutional Ethics Committee

\section{REFERENCES}

1. World Health Organization/Drug Action Program (WHO/DAP). Public Education in Rational Drug Use; Report of an informal Consultation, 23-26 November 1993, Geneva.

2. Montastruct JL, Bagheri H, Geraud T, and LapeyreMestre M. Pharmacovigilance of Self-medication. Therapie. 1997;52(2):105-10.

3. Shankar PR, Partha P, Shenoy N. Self-medication and non doctor prescription practices in Pokhara valley, Western Nepal: A questionnaire based study. BMC Fam Pract. 2002;3:17.

4. Paulo LG, Zanini AC. Self-medication in Brazil. AMB Rev Assoc Med Bras. 1988;34:69-75.

5. Arrais PS, Coelho HL, Batista Mdo C, Carvalho ML, Righi RE. Profile of self-medication in Brazil. Rev Saude Publica. 1997;31:71-7.

6. Loyola Filho AI, Lima-Costa MF, Uchoa E. Bambui Project: a qualitative approach to self-medication. Cad Saude Publica. 2004;20:1661-9.

7. Langefeld S, Press UP, Frentz M, Kompa S, Schrage N. Use of lavage fluid containing diphoterine for irrigation of eyes in first aid emergency treatment. Ophthalmologee. 2003;100(9):727-31.

8. Fraunfelder FT, Meyer SM. Ocular toxicology update. Aust J Ophthalmol. 1984;12:391-4.

9. Fasina O, Ubah JN. Pattern of pre-hospital consultation among ophthalmic patients seen in a tertiary hospital of in South West Nigeria. Afr J Med Sci. 2009;38(2):1737.

10. Eze BI, Chuka-Okosa CM, Uche JN. Traditional eye medicine use by newly presenting ophthalmic patients to a teaching hospital in south-eastern Nigeria: sociodemographic and clinical correlates. BMC Complement Altern Med. 2009;9:40.

11. Kadri R, Hegde S, Kudva A, Achar A, Shenoy S. Selfmedication with over-the- counter ophthalmic preparations: is it safe? Int J Biol Med Res. 2011;2:52830 . 
12. Tayanithi P, Aramwit P. Self-medicated over the counter ophthalmic solutions in central Bangkok. J Med Assoc Thai. 2005;88(4):S330-4.

13. Kagashe GAB, Msela BB. Self-medication among patients seen at four hospitals in daressalaam Tanzania IOSR Journal of Pharmacy. 2012;2(5):21-5.

14. Ajayi IA, Omotype OJ, Ajite KO, Fadamiro CO. SelfMedication Practices Among Patients Seen In a Suburban Tertiary Eye Care Centre in Nigeria. Asian J Med Sci. 2014;5(2):85-90.

15. Berzanskyte A, Valinteliene R, Haaijer-Ruskamp FM, Gurevicius R, Grigoryan L. Self-medication with antibiotics in Lithuania. Int $\mathbf{J}$ Occup Med Environ Health. 2006;19(4):246-53.
16. AI-Azzam SI, AI-Husein BA, Alzoubi F, Masadeh MM, AL-Horani MA. Self-medication with antibiotics in Jordanian population. Int J Occup Med Environ Health. 2007;20(4):373-80

17. World Health Day 2011-Antibiotic resistance: No action today means no cure tomorrow. Statement by WHO Director General-Margaret Chan downloaded 1st October 2012

18. Marquez GE, Pineros-Heilbron H, Sanchez VM, Torres VE, Gramajo AL. Eye Drop Self-medication: Comparative Questionnaire-based Study of Two Latin American Cities. J Clin Exp Ophthalmol. 2014;5:330.

Cite this article as: Gupta R, Malhotra P. Selfmedication in ophthalmology - a northern Indian tertiary hospital experience. Int J Basic Clin Pharmacol 2016;5:2556-60. 